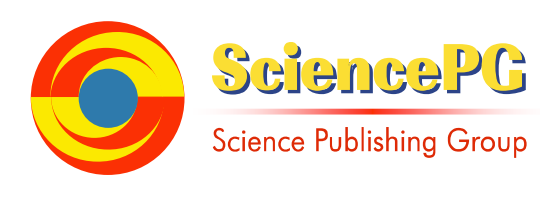

\title{
The Instructional Process: A Review of Flanders' Interaction Analysis in a Classroom Setting
}

\author{
Veronica Odiri Amatari \\ Department of Educational Foundations, Faculty of Education Niger Delta University, Wilberforce Island, Amassoma, Bayelsa State, Nigeria
}

Email address:

dramatariodiri@gmail.com

To cite this article:

Veronica Odiri Amatari. The Instructional Process: A Review of Flanders' Interaction Analysis in a Classroom Setting. International Journal of Secondary Education. Vol. 3, No. 5, 2015, pp. 43-49. doi: 10.11648/j.jisedu.20150305.11

\begin{abstract}
Interaction Analysis is a technique for capturing quantitative and qualitative dimensions of teacher verbal behaviour in the classroom. As an observational system, it captures the verbal behaviour of teachers and students that is directly related to the social - emotional climate of the classroom. It was developed by Ned Flanders out of Social Psychological Theory and was designed to test the effect of social emotional climate on students' attitudes and learning. The theoretical assumptions of Interaction Analysis (IA) are that in a normal classroom situation, verbal communication is predominant; the teacher exerts a great deal of influence on the student and the student's behaviour is affected to a great extent by this type of teacher behaviour exhibited. Flanders' ten category system that attempts to categorize all the verbal behaviour to be found in the classroom is explored in this paper. The objective is the advocacy for the adoption of FIAC in the instructional process in our public schools, since the quantity and quality of teacher - student interaction is a critical dimension of effective classroom teaching and enhanced learning.
\end{abstract}

Keywords: Interaction Analysis, Teacher Talk, Pupil Talk, Indirect Influence, Direct Influence

\section{Introduction}

Classroom communication is a vital ingredient in the instructional and learning process in the school environment. It is as necessary as food is a prerequisite for healthy growth. The quality and quantity of teacher-student interaction is a critical dimension of effective classroom teaching. The term 'interaction' implies an action - reaction or a mutual or reciprocal influence which may be between individuals, e.g. pupil - pupil; teacher-pupil in classroom setting or between materials and individuals or groups. An interaction is usually inferred from the behaviour of persons in the environment being studied. This behaviour maybe verbal or non-verbal and can be classified as being predominantly cognitive, affective or controlling in nature.

Interaction Analysis (IA) is an analytical observation scheme that gives an insight into what a teacher does while teaching. It is a systematic observation that represents a useful means of identifying, studying, classifying and measuring specific variables as the teacher and his/her students interact within instructional learning situation. It uses a system of categories to encode and quantify classroom behaviour of teacher and students.. The purpose of developing the observational system is that a teacher can be trained to use it for analyzing classroom behaviour; for planning, and studying his/her teaching activities in order to create more effective classroom learning. Interaction Analysis as an observational system captures the verbal behaviour of teachers and pupils that is directly related to the social-emotional climate of the classroom.

Interaction Analysis is a process of encoding and decoding the study pattern of teaching and learning. In the coding process, categories of classifying statements are established, a code symbol is assigned to each category and a trained analyst interprets the display of coded data and reconstructs the original events on the basis of the encoded data even though he may not have been present when data were collected. Interaction Analysis is used as a technique capturing qualitative and quantitative dimensions of teacher's verbal behaviour in the classroom.

\subsection{The Basic Theoretical Assumptions of Interaction Analysis}

The various theoretical assumptions, which are basic to every idea of interaction analysis, are as follows:

- In a normal classroom situation, it is verbal 
communication, which is predominant.

- Even though the use of spoken language might resort to non-verbal gestures in classroom, verbal behaviour can be observed with higher reliability than most nonverbal behaviour and also it can reasonably serve as an adequate sample of the total behaviour in classroom.

- We can normally assume that verbal statements of a teacher are consistent with his non-verbal gestures and, in fact, his total behaviour.

- The teacher exerts a great deal of influence on the pupils. Pupil's behaviour is affected to great extent by this type of teacher behaviour exhibited.

- The relation between students and teacher is a crucial factor in the teaching process and must be considered an important aspect of methodology.

- It has been established that social climate is related to productivity and to the quality of interpersonal relations. It has been proved that democratic atmosphere tends to keep work of a relatively high level even in the absence of the teacher.

- Children tend to be conscious of a warm acceptance of the teacher and to express greatest fondness for the democratic teacher.

- The role of classroom climate is crucial for the learning process.

- The teacher-classroom verbal behavior can be observed objectively by the use of observational technique designed to 'catch' the natural modes of behaviour, which will also permit the process of measurement with a minimum disturbance of normal activities of the group of individuals.

- Modification of teacher classroom behaviour through feedback is possible, though how much can change occur and more knowledge relating to the permanence of these changes will require further research.

- Teacher influence is expressed primarily through verbal statements. Non -verbal acts of influence do occur, but are not recorded through interaction analysis. The reasonableness of this assumption rests upon the assertion that the quality of the non-verbal acts is similar to the verbal acts; to assess verbal influence, therefore it is adequately a simple of all influences. ( Niki,2011)

\subsection{Flanders Interaction Analysis Categories (FIAC)}

The development of the original system of interaction analysis was primarily the work of Ned Flanders. Indeed, the system is often referred to as the Flanders System of Interaction Analysis (FIA) - an innovation which made possible significant insights into the analysis and improvement of instruction. Flanders' interaction analysis system is an observational tool used to classify the verbal behaviour of teachers and pupils as they interact in the classroom. Flanders' instrument was designed for observing only the verbal communication in the classroom and nonverbal gestures are not taken into account.

Flanders Interaction Analysis is a system of classroom interaction analysis which is concerned with verbal behaviour only, primarily because it can be observed with higher reliability than can non-verbal behaviour and more also, the assumption made that the verbal behaviour of an individual is an adequate sample of his total behaviour. Flanders Interaction Analysis Categories (FIAC) is a Ten Category System of communication which are said to be inclusive of all communication possibilities. There are seven categories used when the teacher is talking (Teacher talk) and two when the pupil is talking (Pupil talk) and tenth category is that of silence or confusion.

Table 1. Flanders Interaction Analysis Categories (FIAC).

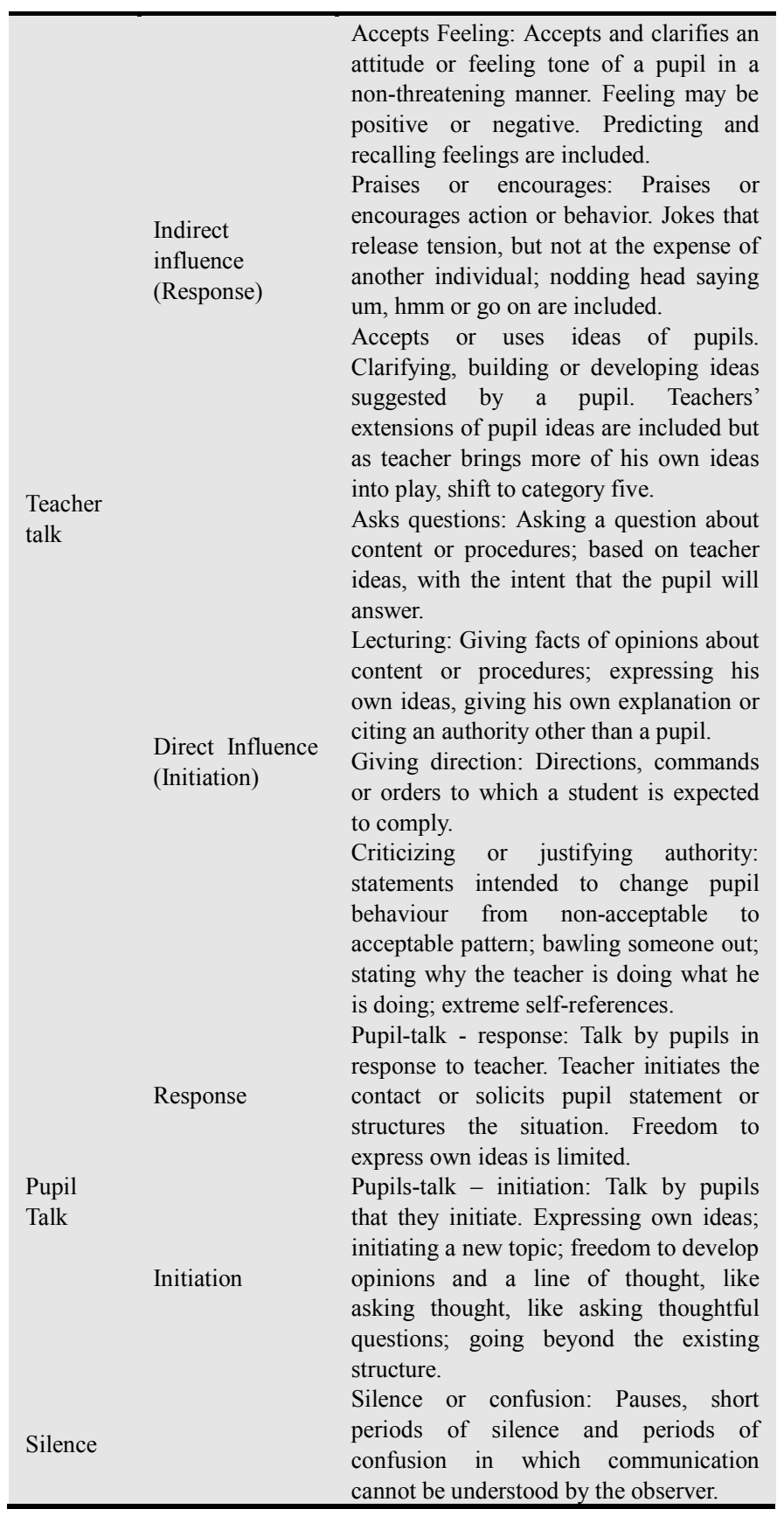

In this system, all teachers' statements are either indirect or direct. This classification gives central attention to the 
amount of freedom the teacher grants to the student. In a given situation therefore, a teacher has a choice. He can be direct, that is minimizing the freedom of the student to respond. His choice, consciously or unconsciously depends upon many factors among which are his perceptions of the situations and the goals of the particular learning situation. In order to make the total behaviour or total interaction in the classroom meaningful, the Flanders system also provides for the categorizing of students talk. A third major section, that of silence or confusion is included in order to account for the time spend in behaviour other than that which can be classified as neither teacher nor student talk. A summary of these categories with brief definitions is given in table 1 .

Reviewing FIAC, a simplified example of a classroom interaction analysis in a teaching/learning process was explored.

\subsection{A simplified Example in a Classroom Situation}

Category 1: Accepts feeling

- Teacher: Why are you sad Preye?

- Preye: Sir, I lost my pocket money

- Teacher: Well, that is enough to make one sad, but cheer up, a replacement will come up.

Category 2: Praises or encourages

- Teacher: How many states are in Nigeria?

- Ebi: 36 states Sir!

- Teacher: Very good. Put your hand together for Ebi.

Category 3: Accepts ideas

- Tokoni: Sir I think a major reason for massive failure among students is ill-preparedness of students towards assessments.

- Fortress: I will like to say that the lack of preparation is as a result of poor reading habit among students.

- Teacher: Tokoni and Fortress had suggested interesting points of view. Fortress buttressed Tokoni's illpreparedness of students by linking it to our societal disregard for a reading culture.

Category 4: Asks questions

- Teacher: What is the difference between dramatization and simulation methods of teaching?

Category 5: Lecture

- Teacher: Social studies education is centered round the desire to proffer solutions to perceived and anticipated problems that arises from man's interaction with the environment. It is a school discipline....

Category 6: Giving directions

- Teacher: Sele, I want you to tell me what you have done with your textbook.

(The degree of freedom that Sele has in response to his teacher's direction determines whether it is a command or direction).

Category 7: Criticizes or justifies authority.

- Teacher: What do you think you are doing out of your seat Femi?

Category 8: Pupil-talk-response

- Teacher: Do you understand?

- Students: Yes (chorus)

\section{Category 9: Pupil-talk-initiation}

- Teacher had just taught on air pollution

A student, not asked for her opinion but stood up to give her experience of inhaling smoke emitted from a running generator and that made her sneezed and coughed for a while to explain effect of air pollution.

Category 10: Silence or Confusion

- Teacher: Bring out your English textbook and open to page 20

- Students: Period of silence and confusion as the students try to find the page

\section{The Coding System}

Flanders Interaction Analysis is a system for coding spontaneous verbal communication. Interaction could either be observed in a live classroom or in a tape recording. Whichever, the coding system is applied to analyze and improve the teacher - student interaction pattern. For every 3 seconds, the observer writes down the category number of the interaction he has observed. He records these numbers in sequence in a column. He will write approximately 20 numbers per minute and at the end of a period of time, he will have several long columns of numbers.

It is best for the observer to spend five to ten minutes getting oriented to the situation before he/she actually begins to categorize. This enables him to have a feeling for the total atmosphere in which the teacher and pupils are working. The observer stops classifying whenever the classroom activity is changed to avoid inappropriate coding. For example, when children are working on workbooks or doing silent reading. He will usually draw a line under the recorded numbers, make a note of the new activity and resume categorizing when the total class discussion continues. At all times, the observer notes the kind of class activity he is observing.

Information is plotted on a matrix for easy analysis and interpretation. The method of recording the sequences of events consists of entering the sequences of numbers into a 10 -row by 10 -column table. The generalized sequence of the teacher-pupil interaction can be examined readily in this matrix.

Adopting the guidelines for coding the verbal interactions of FIAC as expatiated in the preceding paragraph, the following observations are recorded and coded in 2.1; decoded in sequence of numbers in figure 1; the sequence of numbers entered into a 10 -row by 10 -column matrix in table 2 ; and patterns of interaction analyzed in table 3 .

\subsection{A Social Studies Lesson}

Teacher: Boys and girls, please open your social studies book to page 5. (Observer classifies this as a 6 , followed by a 10 because of the period of silence and confusion as the children try to find the page).

Teacher: Wole, we are all waiting for you. Will you please turn your book to page 5 ? (Observer records a 7 and a 6 ).

Teacher: I know now that some of us had a little difficulty with comprehending and were a little disturbed by the study 
of this chapter yesterday. I think that today we are going to find it more exciting and interesting. (Observer records two $1 \mathrm{~s}$, reacting to feeling).

Teacher: Now has anyone had a chance to think about what we discussed yesterday? (Observer records a 4 for a question).

Student: I thought about it and it seems to me that the reason we are in so much trouble in the Niger Delta region is that we haven't really had many opportunities to travel out of the region in order to learn about values of respect and hard work. (Observer records three 8s)

Teacher: Good, I am glad that you suggested that Timi. Now let me see if I understand your idea completely. You have suggested that if we have be exposed to other cultures that appreciate and esteem respect for elders, authority and hard work, we might not be in the trouble we are in today (This is classified as a 2, followed by two 3s)

(Adopted with few modifications - Amidon, E. \& Flanders, N. 1963)

Observer classifies the sequence of numbers recorded above in this fashion.

Table 2. Tabulations are now made in the matrix of $10 \times 10$ to represent pairs of numbers.

\begin{tabular}{llllllllllll}
\multicolumn{2}{l}{ Sample Interaction Matrix } \\
\hline & 1 & 2 & 3 & 4 & 5 & 6 & 7 & 8 & 9 & 10 & Total \\
1 & 1 & & & & & 1 & & & & & 2 \\
2 & & & & & & & & 1 & & 1 \\
3 & & 1 & 1 & & & & & & & & 2 \\
4 & 1 & & & & & & & & & & 1 \\
5 & & & & & & & & & & & 0 \\
6 & & & & & & & 1 & & & 1 & 2 \\
7 & & & & & & & & & & 1 & 1 \\
8 & & & & & & & & 11 & & & 3 \\
9 & & & & & & & & & & & 0 \\
10 & & & 1 & & & 1 & & & & & 2 \\
Total & 2 & 1 & 2 & 1 & 0 & 2 & 1 & 3 & 0 & 2 & 14 \\
\hline
\end{tabular}

Table 3. Measures for analyzing patterns of interaction.

\begin{tabular}{lll}
\hline Type of ratio & Symbol & Calculation \\
\hline \% Teacher talk & TT & $100 /$ total tallies $* \sum$ (cat. \\
\% Pupil talk & PT & $1+2+3+4+5+6+7)$ \\
\% Silence & SC & $100 /$ total tallies $* \sum$ (cat. $\left.8+9\right)$ \\
Teacher Response & TRR & Cat. $1+2+3 * 100 / \sum$ (cat. \\
Ratio & & $1+2+3+6+7)$ \\
Pupil Initiation Ratio & PIR & Cat. $9 * 100 / \sum($ cat. $8+9)$ \\
ID ratio & ID & $\sum($ cat. $1+2+3+4) / \sum$ cat. $\left.5+6+7\right)$ \\
\hline
\end{tabular}

Keys:*=multiplication; /=division; cat=category; $\mathrm{ID}=$ indirect-direct influence.

\subsection{Interpreting the Matrix}

It is generally agreed that no classroom interaction can be ever recreated. The purpose of interaction analysis is to preserve selected aspects of interaction through observation, encoding, tabulating and then decoding.

- The proportion of teacher talk, pupil talk, and silence or confusion: The proportion of tallies in columns 1,2 , 3,4,5,6 and 7; columns 8,9 and column 10 to the total tallies indicates how much the teacher talks, the student talks and the time spent in silence or confusion. After several years of observing, researchers anticipate an average of 68 percent teacher talk, 20 percent of pupil talk and 11 or 12 percent silence or confusion.

- The ratio between indirect influence and direct influence: The sum of column 1, 2, 3, 4, divided by the sum of columns 5, 6, 7 gives this ratio. If the ratio is 1 or more than 1 , the teacher is said to be indirect in his behaviour. This ratio, therefore, shows whether a teacher is more direct or indirect in his teaching

- The ratio between positive reinforcement and negative reinforcement: The sum of columns $1,2,3$ is to be divided by the columns 6,7 . If the ratio is more than 1 then the teacher is said to be good.

- Student's participation ratio: The sum of columns 8 and 9 is to be divided by total sum. The answer will reveal how much the students have participated in the teaching-learning process.

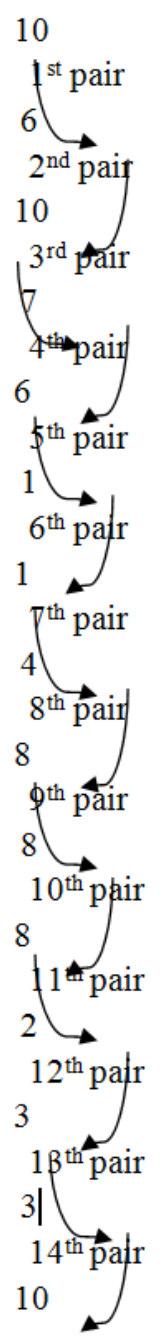

Figure 1. The decoding process.

Note: In most typical classroom behaviour, the 10th category (Silence or Confusion) is usually observed at the beginning or/and at the end of the learning process. However the convention in this system is to add 10 to the beginning and end of the series of numbers as observed above. 


\subsection{Advantages of FIAC}

- The analysis of matrix is so dependable that even a person not present when observations were made could make accurate inferences about the verbal communication and get a mental picture of the classroom interaction

- Different matrices can be made and used to compare the bahaviour of teachers at different age levels, sex, subject-matter etc.

- This analysis would serve as a vital feedback to the teacher or teacher trainee about his/her intentions and actual behaviour in the classroom. The supervising or inspecting staff can also easily follow this system.

- It is an effective tool to measure the social-emotional climate in the classroom.

\subsection{Precautions in the Use of Flanders Interaction Analysis}

- The classroom encoding work should be done by an observer, who is familiar with the entire process and knows its limitations.

- It is an exploratory device therefore value judgments about good and bad teaching behaviors are to be avoided. This technique is not an evaluator device of classroom teaching.

- The questions regarding classroom teaching can only be answered by inspecting the matrix table. The observer cannot answer the question relating to teacher behaviour.

- A comparison between the two matrices can be reliability terms of behaviour ratios, interaction variables and percentage of frequencies in each category and calls for frequency but value judgment is not possible.

- The accuracy of the observation depends upon the reliability of the observer. The classroom recording should be done after estimating the reliability of observers.

- At least two observers should code the classroom interaction for analyzing teaching and teacher behaviour

\subsection{Limitations of Flanders Interaction Analysis}

- The system does not describe the totality of the classroom activity. Some behaviour is always overlooked and who is to say that the unrecorded aspects of the teaching act are more important than those recorded.

- Efforts to describe teaching are often interpreted as evaluation of the teaching act and of the teacher. While descriptions may be used as a basis of evaluation, judgment can be made only after additional value assumptions are identified and applied to data

- The system of interaction analysis is content-free. It is concerned primarily, with social skills of classroom management as expressed through verbal communication.

- It is costly and cumbersome and requires some form of automation in collecting and analyzing the raw data. It is not a finished research tool.

- Much of the inferential power of this system of interaction analysis comes from tabulating the data as sequence of pairs in a $10 \times 10$ matrix. This is a time consuming process.

- Once the high cost of tedious tabulation (electric computers) is under control but the problem of training reliable observers and maintaining their reliability will still remain.

- Its potential as a research tool for a wide application to problems is to be explored.

\section{Discussion}

Flanders Interaction Analysis as a technique for capturing the qualitative and quantitative dimensions of teacher's verbal behaviour is explored in this paper. The objective is the call for the adoption of this technique in the teaching learning process in our primary and secondary schools. Its adoption will impact positively on the social climate of learning that is actually lacking in most of the public primary and secondary schools. It has been established that social climate is related to productivity and to the quality of inter personal relations. The improvement of pupils' interaction and social skills is an important aim of education and this juxtaposes Flanders' technique of Interaction Analysis as a bold step in the right direction to improve the quality of education.

A Problem Based Learning (PBL) curriculum as advocated by our educationalists as a tool to reform our educational system could be argued it will enforce teachers to adopt teaching behaviour that is characterized by indirectness. The National Policy on Education (2013) stipulates that educational activities shall be learner centered for maximum self-development and selffulfillment. Research using FIAC has suggested that the proportion of teacher statements that make use of ideas and opinions expressed by the pupils (sometimes called 'indirectness') is directly related to average class scores on constructive attitudes towards the teacher and the class work; and also, scores higher on achievement tests.(Newman, 2001).Therefore, the appropriateness to train and retrain our teachers in Interaction Analysis (IA), a technique that gives insight into student-teacher exchanges, putting teachers in a better position to analyze and improve their teaching and enhance the social abilities of the students cannot be overemphasized.

Interaction Analysis as a technique should be applied to teacher education in a fashion that is consistent with a philosophy of personal inquiry. Inquiry in teacher education means translating understanding into action as part of the teaching process. It means experimenting with one's own behaviour, obtaining objective information about one's own 
behaviour, evaluating this information in terms of the teacher's role; in other words, attaining self-insight while acting like a teacher.

Flanders argued that established norms in schools are $80 \%$ teacher talk, $20 \%$ pupil talk and $11-12 \%$ silence. This is indeed, the prevalent scenario in our present educational system across the three levels of the primary, secondary and tertiary. There is an earnest need to reverse this scenario. In the traditional teaching situation, it is expected that the teacher shows more initiating behaviour than the pupils. The Pupil Initiation Ration (PIR) measures the proportion of pupil talk that is an act of initiation. A high PIR indicates that students show a lot of initiative introducing their own idea into the classroom discourse. This stimulates the intellectual atmosphere of the teaching / learning process, directed towards a robust development of the individual into a sound and effective citizen, essential for national development.

Interaction Analysis is linked to the personal relationship between teachers and pupils. There is an obvious interplay between the pedagogical authority of the teacher and his way to manage classroom interaction. The quality of verbal interaction is establishing a rapport between the teacher and pupils wherein, the students could easily confide in the teacher their emotions, secrets, ideas and teething problems concerning learning. When a 'free talk' atmosphere is established within the school system, negative influences that are the bane in our present educational system could be curbed.

\section{Conclusion}

It has been found that Interaction Analysis has a lot to offer in the reform our educational system is yearning for. As a system for analyzing verbal behaviour in the classroom, it offers teachers, future teachers and supervisors a tool that can provide objective data about teaching behaviour relevant for instructional improvement. On the other hand, laying a sound basis for scientific, critical and reflective thinking in the education given to our children in schools. An unsatisfactory state of affairs in our present educational system is the type of behaviour teachers exhibit within the classroom that significantly exerts great deal of influence on pupils' behaviour. Therefore, the call for the adoption of FIAC as an effective tool to measure the social emotional climate in the classroom is underscored in this paper.

However, there is a research need for the testing of the hypothetical sample in this review in a live classroom lesson in order to determine the congruence between a theoretical and practical context of FIAC as veritable tool for establishing social climate and interpersonal relations.

\section{Appendix: Coding Procedures FIAC}

General:

- Whenever there is an element of doubt, code according to the prevailing balance of teacher initiation and response

- Rare events should be coded wherever possible

- Categories 1, 2, 3, \& 9 are expected much less than 5, 6, $7, \&$ so use with caution.

Category 1:

- This is a rare event, the teacher must actually label the feeling to obtain this code

Category 2:

- Avoid getting use to code habitually routine superficial exclamations of praise

- Code more than once if extended praise is given

Category 3:

- Teacher can respond to pupil's ideas as in a number of ways.

- Acknowledge - creating norms and logical connections

- Modify, rephrase

- Apply it to solve a problem or make inference

- Compare it with others

- Summarise what is said

- Code 3 more than once if extended response given

- Restrained use in coding 3 appears to enhance its diagnostic utility

- Beware of teacher making too bigger abstraction from pupils statements (code 5)

- Beware of teacher ignoring pupils suggestion and asking for another (code 4)

Category 4:

- Teacher must act as if he expects an answer (not rhetorical question)

- If teacher talk is to bring others into discussion e.g what do you think Joe, no need to code 4.

Category 5:

- Lecturing, expressing opinions, giving facts, interjecting thoughts and off handed comments included.

- In traditional teaching approaches category 5 will be most common, catch all category and incorrect and correct tally for this category unlikely to distort teacher's profile

Category 6 \& 7 :

- Used to indicate close supervision and direction by the teacher

- Used for statements intended to produce compliance. To recognize during coding ask whether compliance will be result of statement

- Avoid confusion with announcements (code 5)

- Questions during teacher directed drill can be coded 6

Categories $8 \& 9$ :

- Making a choice between codes $8 \& 9$ should relate to the teachers preceding question.

Or Not $=$ code 8

Pupil response to open teacher question e.g. what type of dressing should we use $=$ code 9 .

- Student response 8 can turn into 9 if the student embellishes or adds voluntary information or makes an 
independent judgment.

- Use 8 in all cases where there is doubt about 9

- Category 9 also used for students making off target remarks (resistance to compliance)

\section{References}

[1] Amidon, E.J. \& Flanders, N.A. (1963). Interaction Analysis as a feedback system. Interaction Analysis Theory, Research and Application. E.J. Amidon and J.B. Hough. Eds. Philadelphia: Addisn-Wesly publishing company. Inc. Chapter 1: $121-140$.

[2] Amidon, E.J. \& Hunter, E. (1966). Verbal Interaction in the classroom: The verbal interaction category system. Interaction Analysis Theory, Research and Application. E.J. Amidon and J.B. Hough (Eds.) Philadelphia: Addison Wesley Publishing Company. Inc. Chapter 2: 141 - 149.

[3] Federal Republic of Nigeria (FRN). (2013). National Policy on Education (6 ${ }^{\text {th }}$ edition) Abuja: NERDC Press

[4] Gay, L.R.(2000). Competencies for Analysis and Application $\left(5^{\mathrm{TH}}\right.$ ed) Educational Research Florida International University. Pp 448-457
[5] Hafix, M.M; Naseerud din, M \& Ishitiaq, H. (2008).Teacherstudent verbal interaction patterns at the tertiary level of education. Contemporary Issues in Education Research 1, 1: pp 45-50

[6] Inamullah, M. (2005). Patterns of classroom interaction at different educational levels in the light of Flanders' interaction analysis. PhD. Thesis Retrieved Sept.26, 2012, from http://eprintshec.goal.pk

[7] Jasraj, Kaur. (2013). Flanders interaction analysis category system (FIAC). Distance Education PUP

[8] Newman, M. (2001). PEPBL Methodology, Working Paper 6: Flanders Interaction Analysis.

[9] Niki,F.R. (2011). Flanders Interaction Analysis. Retrieved April 23, 2015, from http://www.slideshare.net/selvabarady/flanders-interactionanalysis

[10] Tisher, R.P. (2007) Classroom Interaction Analysis: the new religion. Journal Research in Science Education 2: 35 - 49. 